\title{
Wikis as a Tool for Co-constructed Learning in Higher Education - An Exploratory Study in an Albanian Higher Education
}

\author{
https://doi.org/10.3991/ijet.v16i24.26541 \\ Gerda Sula ${ }^{1}(\underset{\varpi}{ })$, Shqipe Haxhihyseni ${ }^{2}$, Kozeta Noti $^{1}$ \\ ${ }^{1}$ University of Tirana, Tirana, Albania \\ ${ }^{2}$ University Aleksandër Moisiu, Durrës, Albania \\ gerda.sula@unitir.edu.al
}

\begin{abstract}
This study explores the effectiveness of wikis in a teaching course in teacher formation and its pedagogical implications with the aim of determining whether wikis will influence the learning experiences and the learning outcomes of the students in a middle-income, post-communist country as Albania. For this, we implemented student-generated wikis into a master's course on teaching and examined student reflections on their learning outcomes and other pedagogical effects. A mixed method methodology was employed. The findings of the study were informed by triangulating data from the analysis of the student-generated wikis, students' reflections on the experience, as well as a comparison of the learning outcomes based on the exit exams of this group of students and the group of the prior academic year. Our data suggest that wikis help support collaborative learning, but at the same time they also encourage independent thinking. Teachers' authority is minimized, empowering students' ownership and authorship, leading to a continuous process of modification and improvement through interactions among group members via wikis. The data present compelling evidence in favor of wikis, as an organic tool to facilitate co-constructed learning which students seem to enjoy.
\end{abstract}

Keywords—wiki pedagogy, higher education, Albania, collaborative learning

\section{$1 \quad$ Introduction}

This paper expands on wiki use, reviews current literature on wiki usability in education. It builds on the points of view arguing the versatility of the wikis as an interactive, web-based method in encouraging collaborative learning. Then we go on to focus on the learning implications of integrating wikis into the curriculum in higher education and its possible pedagogical implications for higher education. For this, wikis were integrated into an existing course on Learning theories and practices.

Having access to a range of sources beyond the classroom, students nowadays can and do use widely available information to acquire knowledge from. This is at the same time a significant teaching and learning challenge and a great opportunity related to fostering an interactive learning which is focused on the needs of the learners, rather 
than solely based on the perceived importance from the teachers' viewpoints, as stated in [7]. This poses a dilemma to the teacher on how to balance class activity interaction, directed teaching and independent exploration to reach mastery of the subject from the part of the learners. We need to revisit the pedagogical approaches in teaching to benefit from the most efficient use of each of the modalities in our disposition.

To benefit from the current opportunities that Open Education Resources (OER) present in higher education teaching and learning, pedagogical tools are being revisited, in order to effectively engage students, leading to positive learning outcomes through improving the level of engagement. This has been a slow but relentless trend in higher education pedagogy, as shown by [1]. These techniques have shown to successfully improve the learning process, as stated in [18]. Some studies, such as [23] argue that incorporating such pedagogical approaches leads to higher learning efficiency and engagement in the learning process from the part of the students. However, despite the arguments in favor of implementing educational technologies in enhancing students' engagement in their learning through heightened interaction and collaboration in the classroom and outside of it, there are challenges that prevent widespread use.

\section{Wikis as independent and co-dependent pedagogical tools}

As stated in [17], a wiki is a web communication and collaboration tool that can be used to increase students' engagement through collaborating with peers within a supportive environment. Studies investigating the pedagogical implications of wikis confirm that its careful use effectively improve the teaching and learning experience as argued in $[4 ; 7 ; 9]$. However, such studies are scattered, and their focus is more on the technical aspects of using wikis in education rather than their pedagogical implications, making it difficult to reach confirmatory results. Thus, it is timely to focus on the latter. Studies, such as [8] argue that integrating wikis into teaching and learning requires a different approach from direct instruction.

Wiki pedagogy. [20, p.989] describes wikis as an 'architecture of participation'. The wiki is basically an editable web page, which are designed to be simply to use, in order to have users edit web pages alone or in groups. Wikis do not require much training to use, and support is readily and easily accessible to users once they have an account. Wikis allows for text-based projects, but also other multimedia classroom projects that are visually interesting. The focal features of wikis are producing collaboratively, while logging the editing process. The main difference of wikis from learning management systems is its highly social, participatory, and collaborative aspect, as stated in [17;9].

Although debates on the extent to which students benefit from the opportunities that digital technologies offer on their learning are still strong as [27] argues, there is no doubt that the learning outcomes are improved when such technologies are put to use for educational purposes, as stated in $[5 ; 13]$. Being that the benefits of these technologies when used interactively and when engaging the social collaboration of the students are evident, as clarified by [1], the curricula and the pedagogical approach in higher education needs to be reconfigured in order to include educational technologies in their teaching and learning frameworks. Wikis can offer interactive and social negotiations to students, as such it is an opportunity to be considered. Through making use of wikis 
as a learning activity, students are empowered to contribute, as there is the opportunity for improvement by others, lowering the stakes of mistakes, and encouraging sustained learning in an unstructured learning environment. The authority of the teachers is reduced, as teachers can learn from their students, being that they might make a more updated contribution to the phenomenon that is being discussed, as referred by [4].

Wiki pedagogy learning paradigms. There are two possible learning paradigms in using wikis for higher education learning: collaborative learning paradigm and the constructivist paradigm, as stated in [9]. The behavioral learning paradigm, the oldest and the most prominent paradigm, considers learning as determined externally, not from the learner, based on the assumption that knowledge is objective, and it should be acquired logically. The constructivist learning paradigm assumes that the knowledge is socially constructed and not determined externally, and the learner is actively involved in co-creating it. The main features of the wikis are that they facilitate student-student and student-teacher communications and collaborations in a free and flexible learning environment, encouraging co-constructing knowledge, as stated in [2;6]. As such, the wikis pedagogies belong to the constructivist learning paradigm. Their capacity to help groups work together toward a shared understanding support the shift towards learnercentered, as they allow a co-construction of the meaning through not only sharing knowledge but encouraging constructing it jointly. The main feature is student-to-student and student-to-teacher interaction, forming a learning partnership, as a more knowledgeable student or the teacher can edit an entry of another student, which is no longer valid. There is a vast evidence confirming that wikis support peer interactions, empowering, collaborative learning, sharing, group work, leading to a heightened sense of learning community. The collaborative skills that wikis seem to significantly contribute to build are the foundations of the workforce skills required by the employees in the future, as stated in [16].

Using wikis in higher education - not only advantages. In the previous paragraphs we presented some of the advantages of wikis in nurturing an effective learning environment, most importantly promoting collaboration (e.g., 20; 8; 10]. However, grading the students at the end of the semester might undermine this potential of using wikis, being that grading can be seen as competitive. This high stake characteristic can undermine the wiki pedagogy to be implemented successfully, as proposed by $[5 ; 8 ; 20]$. The nature of wikis stands in juxtaposition with the nature of higher education structuring (collaboration vs. competition). As stated in [9], even though many students participated in a wiki when it was designed as a compulsory assignment, most participated superficially, without meaningful engagement in their contributions. However, the students that were actively engaged in wiki-related activities reported a deeper learning, and a sense of authorship, as stated in [11,24]

Other studies explore the heightened responsibility of performing their best due to the consciousness of the students of an audience and not just doing an assignment for the eyes of the teacher only. This led to an improved collaborative learning, as stated in $[20]$.

Thus, integration of wiki activities in higher education learning improves students' constructive writing, as one of the steppingstones leading to improved learning outcomes [24]. Such claims were supported by other studies as well, as stated in $[1 ; 20$; 
11] finding that using wikis helps students understand the material better, leading to heightened learning outcomes, compared to students that didn't use wikis. Moreover, cooperation, positive dynamics, increased confidence, and sharing were reported to be of significant benefits of wiki-related activities, as presented by [8].

This study aims to explore the learning effects on the use of Wikis in the Albanian higher education students, and the pedagogical implications of including wikis to improve learning outcomes of the students. The subject is learning theories and practices, which is part of the Master's program curriculum in teacher formation. All papers should begin with an introduction that sets the stage for the discussion. For some disciplines, it is more appropriate to use Background as an alternative first section.

\subsection{Specific context - Albania}

Albania, even though it was part of the communist block after World War II, did not embrace the idea of equality and social justice in the field of education and in school systems as other communist countries did. Instead, the concept of "proletariat dictatorship" system was imposed, creating distinction between classes, persecuting mostly well-educated individuals who had studied in the West and their families, not allowing their offspring to attend higher education.

Since the collapse of communism in 1991, Albanian higher education has had to balance between massification, dealing with the rigid authoritarian past while trying to prepare students for a global workforce and lack of adequate funding. During the last 30 years, the number of students enrolled in Albanian universities is almost 10 times as high. Yet, Albanian government invests around 0.6 percent, on higher education, ranking the country in those that puts the smallest proportion of its GDP in higher education. Higher education had to reinvent their goals, with the aim of developing a generation with democratic values, and critical mindset, able to constructively tackle issues innovatively. This philosophy changes radically from the previous one, which was focused on obedience and transmitting knowledge, which was centrally controlled by the state.

While higher education has become more accessible to larger numbers, its quality has suffered dramatically, both in the offer of education, but also in the conceptualization of higher education as a tool for developing highly skilled workers, equipped with the qualities required in the global job market, as stated in [14]. In the 21st century, the occupation-specific skills do not suffice to meet the needs of labor markets. Employees are nowadays expected to have employability skills. Most highly ranked among them are communication skills, problem-solving and decision-making skills, IT literacy and teamwork skills. Other personal attributes include willingness to learn, flexibility and adaptability, self-confidence, creativity and initiative, independence, self-awareness, emotional intelligence, stress tolerance, reflectiveness, and lifelong learning.

\subsection{Case description}

The subject Learning theories and practices belongs to the pedagogical block of subjects in preparing future teachers of foreign languages. The pedagogical subjects have a transversal learning outcome, which is to provide students with the knowledge and 
skills to critically analyze their own learning experience, so that they can improve their professional development as teachers. In short, they are encouraged to reflect on their learning and the teaching of their teachers, so that they can improve professionally. Using wikis as a learning activity has therefore a multifold purpose: to help the students learn more efficiently the subject taught through co-constructing learning, as presented beforehand.

For wikis, we used Wikipedia, as a platform that is known to students, but only as users, not as authors. None of the students had contributed to a Wikipedia article before this assignment.

The subject was taught during the fall semester 2018 -2019. The semester is 15 weeks long, from 20 October to 30 March. 120 students enrolled in this course participated in the wiki assignment.

The assignment was organized around group work. The students had to form groups of four and search for a topic in Wikipedia, whether in Albanian or in the foreign language that they were studying, which was improvable and they had to defend their proposal $(10 \%)-18$ February; they had to present the references and argue their importance $(30 \%)-4$ March; they had to draft the first contribution for other wikipedians to comment on $(20 \%)$ - 11 March; publish it $(30 \%)$ - by 18 March and write an individual reflective essay $(10 \%)$ - on 25 March. Wikipedians or editors are the volunteers who write and edit Wikipedia's articles, unlike readers who simply read, as stated in $[26 ; 25]$. For the essay, students were required to reflect on their experience in writing wikis and include important insights that they gathered from this experience to reflect on how they could use wikis in their own teaching in the future. During the whole semester, they could contact the teaching team during weekly office hours regarding the preparation of their work. Each student had to have their personal account and their contribution would be assessed individually, leading to a difference in grading between students of the same group, with the same output. So, students were working jointly, while being held individually accountable for their contributions. Such design was based on the literature presented beforehand, as stated in [1], which confirm the importance of wikis as a collaborative tool.

The assignment was designed in an escalating difficulty, based on Bloom's taxonomy as revised by [12], from explaining their choice, to analyzing existing literature, to synthetizing their work in a written format, to reflecting personally on their experience. It was expected that the wiki experience would support students not only to learn how to structurally arrange their information, but also to share newly acquired knowledge, defend their choices, synthetize their knowledge, negotiate what to include in their writing collaboratively. The students received assessment strategies and requirements on how to participate in the finalization of their wikis and how to write a reflective essay based on this experience.

\section{$2 \quad$ Method}

A mixed method approach, including multiple methods to investigate students' learning outcomes through wiki pedagogy was employed as specified in [21]. Thus, the 
danger of relying on one single research method was negated, as stated in [3, 4, 22]. In the current study, we used a triangulated research method, involving three research methods together with the analysis of two data sources. First, to identify emerging themes related to students' learning experiences during the wiki assignment, we employed a critical incident method of the reflective essays related to the wiki experiences in which the students worked, by asking students to describe two positive and two negative experiences, and two insights related to the usability of the wiki pedagogy in their future teaching. The analysis was carried out by Nvivo software. Second, to further comprehend wikis pedagogical implications in higher education, as well as to analyze the impact of the wikis on the learning outcomes, we compared the exit exam results of this group of students with the exam results of the students of the same course from the previous year $(\mathrm{N}=98)$. They are comparable, as their average GPA of their Bachelor's degree is comparable with each other with the students participating in wikis $(\mathrm{N}=120)$ average GPA of 7.8/10 and the group not participating in wikis average GPA of 7.9/10. Even though the exam is not standardized, the test covers the same issues, maintains the same learning outcomes for the students and has been taught by the same group of teachers. The only different variable between the groups was the wiki assignment. We hypothesize that the students working on the wiki will perform better in the exit test.

Empirical data gathered from these primary sources informed the findings of the study.

\subsection{Population}

There were $\mathrm{N}=120$ students enrolled in this course. They were aged between 22-27 years, $24 \%$ male and $76 \%$ female. There were $10 \%$ of them who were teachers, opting to continue their education. The course is part of the compulsory subject of the teacher preparation program for teachers of foreign languages. The students improved 30 articles in Wikipedia, of which 17 in Albanian, 11 in English and two in French. The articles had to be related to theories and practices of learning, which was the subject they were taking. They had to defend their choice in front of other students and the teaching staff.

The purpose of the content analysis of the wiki articles which was carried out was to explore possible pedagogical implications of wiki assignments, rather than assessing how the students performed on the assignments, as stated in [16].

To gain an in-depth understanding of the pedagogical implications of the wiki assignment in students' reflection, as proposed in [21], the critical incident method was adopted. All students were asked to write two positive and negative experiences with wikis and two insights related to the usability of the wiki pedagogy in their future teaching on the submission day of the assignment.

The content analysis was carried out as follows. Using Nvivo software, a microanalysis was performed on the content of the student-generated wiki articles on Wikipedia, following the history of the entries, and the comments of the community of wikipedians. The written text of the student essays assignments was analyzed as well. Open, axial, and selective codings were assigned. Based on the similarities and differences of the codes, categories and subcategories were formed. Properties, dimensions, and the 
relationships among the categories were noted, as stated in [15]. Completing the analysis, two thematic categories were derived.

\section{Discussions}

The two main thematic categories will be used as key findings of this study, which will be helpful in our discussion regarding the pedagogical use of wikis in higher education: (1) learning Experience and (2) Technological issue. In this article we will focus solely on exploring the pedagogical implications of using wikis as a learning activity in higher education, giving us insights on the learning experiences of the students and the eventual learning outcomes. The technological issues are contextual-based and related to the specificities of Albanian higher education, which is not the main interest of this article. Further, we will explore (3) learning outcomes through a quantitative analysis.

Table 1. Thematic categories

\begin{tabular}{|c|c|c|}
\hline Theme & Subtheme & Key words \\
\hline Learning experience & $\begin{array}{c}\text { Collaboration } \\
\text { Heightened individual learning } \\
\text { Individual accountability } \\
\text { Flexibility of work } \\
\text { Independent thinking } \\
\text { Early hesitancy } \\
\text { Teamwork }\end{array}$ & $\begin{array}{c}\text { Together, efficient activity, influence of thinking, } \\
\text { individual contribution, individual responsibility, } \\
\text { flexible timing, flexible location, novelty, broad, } \\
\text { unstructured }\end{array}$ \\
& & \\
\hline
\end{tabular}

\subsection{Learning experience}

We numbered wiki articles (p. e. W1 means wiki article from the group number one) and student essays (E1 means essay of the student number one), instead of students, so that we could avoid identifications, in alignment with ethical research protocols.

Table 2. Excerpts illustrating collaboration during the wiki assignment

\begin{tabular}{|l|c|}
\hline \multicolumn{1}{|c|}{ Excerpts from the wiki articles } & W \\
\hline In our discussions, we learned... & 16 \\
\hline In line with our reflections... & 6 \\
\hline Most of us agreed that ... & 5 \\
\hline The different perspectives presented by some of us... & 28 \\
\hline Our group progression suggests... & 12 \\
\hline The different perspectives presented helped us look at the issue at hand... & 29 \\
\hline Based on our group research, we conclude with these implications... & 21 \\
\hline Excerpts from reflective essays & E \\
\hline Reflecting back on other's comments... & 22 \\
\hline I shifted my view... & 119 \\
\hline As I discussed my opinions and ideas with others... & 13 \\
\hline
\end{tabular}


Paper-Wikis as a Tool for Co-constructed Learning in Higher Education - An Exploratory Study in...

\begin{tabular}{|l|c|}
\hline \multicolumn{1}{|c|}{ Excerpts from the wiki articles } & W \\
\hline $\begin{array}{l}\text { Our group continued to discuss without stopping at one option, and considered arguments that other } \\
\text { students brought to the discussions to form a more consolidated idea... }\end{array}$ & 78 \\
\hline We finally agreed that... & 85 \\
\hline $\begin{array}{l}\text { However, one member of our group continued to keep their entry, even with our long discussions } \\
\text { that ... }\end{array}$ & 101 \\
\hline Trying to understand other students' different point of view, I was... & 87 \\
\hline Despite all the different views expressed by other students, we managed to conclude that ... & 19 \\
\hline As a result of our discussions, I understood that... & 61 \\
\hline $\begin{array}{l}\text { At first, I thought that this was an easy assignment. But our negotiation and discussions continued } \\
\text { throughout the whole semester. }\end{array}$ & 36 \\
\hline
\end{tabular}

The discussions presented above show heightened learning and a collaborative learning experience through wikis. It is important to note that, although students were advised to start with their search from the beginning of the semester, some students started later (p. ex. E54 when answering on the negative aspects of the task: "I accepted the theme that other members of our group suggested and got involved only when I had to hand in my references. I think that this was a mistake, as I could have been more efficient should I have used the time at the beginning." Then the students had a hard time to stop working, as they were receiving feedback and comments from other wikipedians (E23: "I wish we had more time to improve our comments based on the contributions from wikipedians. I feel that our discussion is not finished.").

There are other important findings regarding their experience with wikis:

Accountability. Each student was accountable for their contribution, so they found themselves involved in the task. One student comments: "Usually, I enjoy group work, because I can benefit from others' work. This assignment, even though was a group work, made me work individually. It was very hard work." (E73) Another one notes: "I usually do the work and put other people's name on it. This time I had to discuss it with others, and it was not easy." (E120)

Flexibility of working from everywhere, anytime. The semester when this study was conducted saw a massive protest from the students, resulting in halting face-to-face classes for a month. But the students kept on working on the wikis, because they could. "We didn't have to arrange when to meet, but we could do it whenever we could individually, as it was easy to see what others had contributed." (E47) "I could catch up easily on the discussion thread. I think this was a good thing to have." (E13)

Independent thinking. Students could develop their own opinion thanks to the constructive argument nature of the wiki assignment. "I truly appreciated the comments that a wikipedian made in our article, stating that it might not be the case, as there were other research stating a different viewpoint." (E82). The students then could use these interventions collaboratively to shape independent thinking. "What we understood from reading the discussions was that the reason... (W17)" Another one states "Although I did agree with most of what others had said, I strongly believed that... I did not manage to change others' idea about it, however." (E96) S/he goes on to state "I am pleased that my concept is part of the Wikipedia article, as there are not always right and wrong answers, and contradicting views are normal in education." (E96) According 
to other students, wiki discussions helped them embrace the idea that there are times when nuances, instead of only one right answers, are valuable.

Early hesitancy. The novelty of using wikis as a learning assignment withdrew many students from engaging early in the task. "At first, when I learned about the assignment, I was hesitant to contribute, because it was not the usual assignment." (E15) Others were waiting for the contributions of other students in order to understand how to interfere: "I was peeking on others' wikis, because it was not easy to engage." (E72). Also, the freedom to choose the topic was intimidating to them: "Deciding what to focus on was the most difficult task." (E91) However, despites the slow start, in each group an early adopter was identified, who served as a leader for the rest of the group (based on the teachers' observations of the wiki histories of entries). The spontaneous leadership showed to be very beneficial for the others: "I did not write at first, because I was hesitant of making a mistake. However, after [another student] wrote in our WhatsApp group, it pushed all of us to continue where she stopped." (E78)

However, after the slow start, the level of entries increased, reaching some 15,350 words. This entry was the final input from the students, after the drafts had been finalized and approved by wikipedians, turning them into published authors in Wikipedia. The fact of being published and read by others was an issue causing high pressure, but also a heightened level of pride for many "My dad cannot believe it that I am a published author (smiley face)!” (E65)

Students faced difficulties in splitting the responsibilities, leading to several writing about the same issue. This caused tiredness and stagnation, slowing down the learning process. "We kept on writing about the same thing, and this caused not little friction amongst us." (E54)

Teamwork. Students seem to appreciate the transparent and accountable nature of teamwork created during the wiki assignment and they consider that wiki-related activities can support students to develop soft skills, such as negotiation, exploring of resources, critically finding solutions outside the subject curriculum, supporting each other, appreciating strong skills of other members of the team, all very important skills for the future employees. "I have participated in group assignments before, but I have never worked so closely with the other members of the group as in the wiki task. It was very challenging, time consuming, but I have learned so [underscored by the student] much from others." (E01)

We could thus conclude that, aligned with previous studies $[1 ; 24]$, the wiki activity offered to our students, showed to be an efficient tool in enhancing true collaborative learning among them. The history of entries and revisits of their input showed that individual students were influenced in their thinking by the joint work evolving through wiki discussion. Excerpts from the students' reflections show the influence that other students had on their own learning.

\subsection{Reaching learning outcomes}

An independent-samples t-test was conducted to compare learning outcomes of this subject in students that implemented the wiki as a learning activity and in students that did not. Both groups are master's students in Teaching of foreign languages, the subject 
and its learning outcomes remain the same, and so do the teaching staff. The exit exam, which was used to compare the learning outcomes is comprised of 50 points, and the nature of the questions is comparable. The test was designed by the same teaching staff in both academic years: $(\mathrm{N}=120)$ academic year 2018-2019 (with wiki activity) and $(\mathrm{N}=98)$ academic year 2017-2018 without wiki activity. We employed SPSS version 25 for the analysis.

There was a significant difference in the scores for wiki group $(\mathrm{M}=41.50, \mathrm{SD}=3.99)$ and no wiki group $(\mathrm{M}=37.02, \mathrm{SD}=9.72)$ conditions; $\mathrm{t}(166)=-3.99, \mathrm{p}<0.01$ (cf. Table 3).

Even though the tests are not controlled for homogeneity of variances, it is important to keep in mind such effect on the performance of the students in reaching the learning outcomes.

Table 3. t-test results comparing exit exams of groups involved or not in a wiki activity

\begin{tabular}{|c|c|c|c|c|c|c|c|c|c|}
\hline & Group & n & Mean & SD & F & Sig. & t & df & Std. Error Mean \\
\hline \multirow{2}{*}{ Exam points } & Without wiki & 120 & 37.02 & 9.72 & 36.12 & $.00^{* *}$ & -3.80 & 166 & 1.02 \\
\cline { 2 - 10 } & With wiki & 98 & 41.50 & 3.99 & & & & & .45 \\
\hline
\end{tabular}

Note: $* *$ indicates $\mathrm{p}<.01$

These results suggest that involvement in a wiki activity related to the subject at hand really does influence the learning outcomes of the students. Specifically, our results suggest that when students participate in wiki activities, they perform better in the exam designed to measure the overall learning outcomes of the subject at hand.

\subsection{Country-specific discussion: Albania}

$100 \%$ of the students involved in this experience confirmed that they had never participated in generating wikis as a learning opportunity. They reported to face difficulties in completing the task due to a) low IT literacy; b) poor academic writing skills, leading to breaches in referencing and plagiarism, which were reported by wikipedians in English language; c) low level of team working skills. However, the students' performance at the end of the subject, and their reflections on the experience leads us to believe that such activities help students develop important work-related skills, such as team working and IT skills, communication among peers, problem-solving and decision-making skills. Students report an increase on the willingness to learn, flexibility and adaptability to each other's timetable and skill, and a boost in self-confidence when the article has been approved. Creativity and initiative, independence, self-awareness, emotional intelligence, and reflectiveness are also skills reported to have been improved by the students. Previous studies confirm that, for the wiki assignment to have an impact on students' learning, it is important to have a clear curriculum alignment, as stated in [7].

Overall, many students found that the wikis positively influenced their learning outcomes, and such finding was confirmed by the statistical analysis, showing a significant difference in the learning outcomes between this group and another group that had not participated in a wiki-related activity. The discussions developed by the students in 
completing their wiki assignments supported collaborative knowledge, which apparently led them to a deeper learning, and a sense of authorship compared to students that had not had the opportunity to work in a wiki assignment.

\section{Conclusions}

The focus of this study was to explore possible pedagogical implications when integrating wikis in an existing curriculum of a subject in teacher preparation. Our focus was in exploring possible pedagogical implications from the use of wikis. The findings offer some interesting pedagogical opportunities for teaching and learning in higher education, along with some challenges. The following discussion presents a series of reflections based on the findings of our study, to guide higher education teachers in including Wikis as a learning experience in higher education.

Consistent with previous research [11], our data suggest that wikis help support collaborative learning, but at the same time they also encourage independent thinking. Teachers' authority is minimized, empowering students' ownership and authorship, leading to a continuous process of modification and improvement through interactions amongst group members via wikis. A wiki activity uses a constructivist learning paradigm and tends to challenge the authority of teachers, thus higher education teachers should be prepared to let go and to have their power questioned. The data present compelling evidence in favor of wikis, as an organic tool to facilitate co-constructed learning which students seem to enjoy.

However, the involvement of the students was not equally qualitative, creating leaders and laggards within the group. As discussed earlier in the findings, the novelty and the unfamiliarity with wikis as a learning tool tended to deter active wiki engagement by some students. In alignment with previous studies on the diversity in levels of engagement when involved in technology aided learning, as stated in [9], we found that the levels of engagement in the wiki articles were different within the members of the group: while some students enthusiastically and consistently participated in the different sections of the wiki assignment, others were hesitant to contribute, and their level of involvement was more basic until the end of the assignment.

We believe that the design of our wiki in alignment with the learning outcomes of the subject's curriculum overall, better supported students in reflecting on the wiki assignment, leading to better learning outcomes for students.

Our study explored the effectiveness of wikis in a teaching course in teacher formation and its pedagogical implications. In alignment with previous research, such as $[8 ; 20]$, we found that wikis help collaborative, co-constructed learning, while supporting independent thinking and providing students the opportunity to confront their views and opinions with those of others and the most up-to-date literature. Moreover, thinking and writing reflectively support students construct the aimed knowledge for the course.

We conclude that well-designed wiki activities, aligned with learning outcomes of the subject has the potential to support a more efficient learning of higher education students in countries with low GDP in higher education, and countries transitioning to 
Paper-Wikis as a Tool for Co-constructed Learning in Higher Education - An Exploratory Study in...

democracy, such as Albania. We consider this to be the most important takeaway from our research.

\section{$5 \quad$ Recommendations for future studies}

We recommend setting clear guidelines and support structures on the level of individual contribution for future wiki practice. A diagnostic assessment is necessary prior to embark on wiki learning activities, to offer the required support based on disaggregation of students' skills. A task distribution throughout the semester, especially if students are not familiar with wikis is recommended as well.

Moreover, we are cautious to allocate all the merits to the wiki activity, as we had not conducted a pretest with both groups, which would help us get to sounder conclusions. A more thorough quantitative design in measuring effects of the wikis in the learning outcomes of the subject is therefore strongly suggested.

\section{$6 \quad$ References}

[1] Altanopoulou, P., Tselios, N., Katsanos, C., Georgoutsou, M., \& Panagiotaki, M. (October 2015). Wiki-Mediated Activities in Higher Education: Evidence-Based Analysis of Learning Effectiveness Across Three Studies. Journal of Educational Technology \& Society Vol. 18 , No. 4, 511-522.

[2] Bada, S. (2015). Constructivism Learning Theory: A Paradigm for Teaching and Learning. IOSR Journal of Research \& Method in Education (IOSR-JRME) (V. 5/6/1), 66-70.

[3] Boulaajoul, M; Aknin, N. (2019). The Role of the Clusters Analysis Techniques to Determine the Quality of the Content Wiki. IJET Vol 14, No 01, 150-158. https://doi. org/10.3991/ijet.v14i01.9074

[4] Butcher, H., \& Taylor, J. (2008). Using a wiki to enhance knowing participation in change in the teaching-learning process. Visions: The Journal of Rogerian Nursing Science, 15:1, 30-44.

[5] Davies, A., Pantzopoulos, K., \& Gray, K. (2011). Emphasizing assessment 'as' learning by assessing wiki writing assignments collaboratively and publicly online. Australasian Journal of Educational Technology, 27(5). https://doi.org/10.14742/ajet.932

[6] Dhindsa, H., Makarimi-Kasim, \& Roger Anderson, O. (2011). Constructivist-Visual Mind Map Teaching Approach and the Quality of Students' Cognitive Structures. J Sci Educ Technol 20, 186-200. https://doi.org/10.1007/s10956-010-9245-4

[7] Gray, K., Thompson, C., Sheard, J., Clerehan, R., \& Hamilton, M. (2010). Students as Web 2.0 authors: Implications for assessment design and conduct. Australasian Journal of Educational Technology, 26(1). https://doi.org/10.14742/ajet.1105

[8] Harrell, L. (2013). A Learner Centered Approach to Online Education. Charlotte NC: Information Age Publishing.

[9] Hewege, C., \& Perera, L. (2013). Pedagogical significance of wikis: towards gaining effective learning outcomes. Journal of International Education in Business, V. 6, I1, 51-70. https://doi.org/10.1108/18363261311314953

[10] Judd, T. (2018). The rise and fall (?) of the digital natives. Australasian Journal of Educational Technology, 34(5). https://doi.org/10.14742/ajet.3821 
Paper-Wikis as a Tool for Co-constructed Learning in Higher Education - An Exploratory Study in...

[11] Judd, T., Kennedy, G., \& Cropper, S. (2010). Using wikis for collaborative learning: Assessing collaboration through contribution. Australasian Journal of Educational Technology, 26(3). https://doi.org/10.14742/ajet.1079

[12] Kim, M., \& Kim, S. (2020). Dynamic learner engagement in a wiki-enhanced writing course. J Comput High Educ. https://doi.org/10.1007/s12528-019-09248-5

[13] Krathwohl, D. R. (2002). A Revision of Bloom's Taxonomy: An Overview. Theory into Practice, 41:4, 212-218. https://doi.org/10.1207/s15430421tip4104 2

[14] Lu, J., Lai, M., \& Law, N. (2010). Knowledge Building in Society 2.0: Challenges and Opportunities. In S. I. Khine M., New Science of Learning. (p. 553-567). New York, NY: Springer. https://doi.org/10.1007/978-1-4419-5716-0 27

[15] Malone, M. (2018, January 18). The challenges of using technology in Albanian schools: SILO. Retrieved from https://silo.tips/download/the-challenges-of-using-technology-in-albanian-schools

[16] Meishar-Tal, H; Tal-Elhasid, E. (2008) measuring collaboration in educational wikis - a methodological discussion. iJET - Volume 3, Special Issue 3: "ICL2008, 46-49 https://doi.org/10.3991/ijet.v3i1.750

[17] Moghaddam, A. (2006). Coding issues in grounded theory. Issues in Educational Research, Vol 16, 52-66.

[18] OECD. (2019). OECD Employment Outlook 2019: The Future of Work. Paris: OECD Publishing. https://doi.org/10.1787/9ee00155-en

[19] Parker, K., \& Chao, I. (2007). Wiki as a Teaching Tool. Interdisciplinary Journal of Knowledge and Learning Objects Volume 3. Retrieved from https://doi.org/10.28945/3131

[20] Pounds, A., \& Bostock, J. (2019). Open educational resources (OER) in higher education courses in aquaculture and fisheries: opportunities, barriers, and future perspectives. Aquaculture International, 27, 695-710. https://doi.org/10.1007/s10499-019-00355-9

[21] Sulisworo, D (2012). Designing the Online Collaborative Learning Using the Wikispaces. IJET, Vol 7, No 1, 58-61 https://online-journals.org/index.php/i-jet/article/view/1863 Vol 7, No 1 (2012). https://doi.org/10.3991/ijet.v7i1.1863

[22] Tashakkori, A., \& Teddlie, C. (2010). SAGE Handbook of Mixed Methods in Social \& Behavioral Research. Los Angeles California: Sage Publishing. https://doi.org/10.4135/ 9781506335193

[23] Wheeler, S., Yeomans, P., \& Wheeler, D. (2008). The good, the bad and the wiki: Evaluating student-generated content for collaborative learning. British Journal of Educational Technology, 39(6), 987-995. https://doi.org/10.1111/j.1467-8535.2007.00799.x

[24] Wikipedia. (2020, 07 03). Retrieved from https://en.wikipedia.org/wiki/Wikipedia:Wikipedians\#cite note- 2

[25] Wikipedia. (2020, July 03). contributing to Wikipedia. Retrieved from https://en.wikipedia.org/wiki/Wikipedia:Contributing to Wikipedia.

[26] Wikipedia statistics. (2018, December). Retrieved from https://stats.wikimedia.org/EN/ TablesWikipediaSQ.htm

[27] Woo, M. M., Chu, S. K., \& Li, X. (2013). Peer-feedback and revision process in a wiki mediated collaborative writing. Educational Technology Research and Development, 61(2), 279-309. https://doi.org/10.1007/s11423-012-9285-y 
Paper-Wikis as a Tool for Co-constructed Learning in Higher Education - An Exploratory Study in..

\section{$7 \quad$ Authors}

Gerda Sula is a lecturer, part of the Department of Pedagogy and Psychology Faculty of Social Sciences, University of Tirana, where she teaches educational technologies and learning. She often serves as a consultant for several organizations related to educational issues.

Shqipe Haxhihyseni is a lecturer in educational sciences at the Faculty of Education, University Aleksandër Moisiu Durrës, where she holds the position of Vice-Dean. Her main professional interest areas are teaching methods and curriculum design and development.

Kozeta Noti, lecturer at the Department of Pedagogy and Psychology, Faculty of Social Sciences, University of Tirana, passed away as the article was being drafted. Her contributions in writing this article and in the professional and personal life are outstanding. This article is in her memoriam.

Article submitted 2021-08-26. Resubmitted 2021-10-16. Final acceptance 2021-10-17. Final version published as submitted by the authors. 